\title{
Nocturnal Labor Activity: Impacts on Nursing Professionals Health
}

\section{Renata Perazzo Carvalho*, Maria Eduarda Carvalho, Alex Bernardo Silva, Juliana Gonçalves Rocha, Mauricia Figueiroa Silva, Francimar Nipo Bezerra, Mayrla Lima Pinto and Luiz Ataide Junior}

Federal University of Pernambuco, Brazil

*Corresponding author: Carvalho RP, Federal University of Pernambuco, Brazil, Tel: 558121268000, E-mail: perazzo_renata@hotmail.com

Received date: March 21, 2017; Accepted date: March 25, 2017; Published date: March 31, 2017

Copyright: (C) 2017 Carvalho RP, et al. This is an open-access article distributed under the terms of the Creative Commons Attribution License, which permits unrestricted use, distribution, and reproduction in any medium, provided the original author and source are credited.

Citation: Carvalho RP, Maria EC, Alex BS, et al. Nocturnal Labor Activity: Impacts on Nursing Professionals Health. Arch Med. 2017, 9:2

\section{Abstract}

Objective: Describe the effects related to sleep disorders in nursing professionals with nocturnal labor activity.

Method: A descriptive transversal study with a quantitative approach. There were 184 participants in this research, including 46 nurses, 133 nursing technicians and 05 of them were excluded as losses. We used the chi-square test and Fisher's exact test for the intersection of responses between the categories.

Results: $53.1 \%$ of them presented diseases as consequences of the nocturnal labor activity, which were: sleep disorders (26.8\%), hypertension (17.3\%), spinal problems $(16.2 \%)$, gastritis $(11.7 \%)$ and vascular problems (10.1\%).

Conclusion: The changes in the circadian cycle, developed by the nocturnal labor activity have a negative impact on health and life of nursing professionals.

\section{Keywords: Sleep; Sleep deprivation; Nursing team}

\section{Introduction}

"Sleep is a natural biological process, fundamental for the human being's life, constituting a complex physiological state and one of the great mysteries of neuroscience"[1]. Scientifically, it is explained as an amount of brain electrical activities with physiological and behavioral changes, besides having a function of recomposition, protection and conservation of energy [2].

"Melatonin, which is secreted by the pineal gland, due to low Clarity, is the key for the beginning of the wake-sleep cycle."

"Sleep is divided into two distinct physiological states, called the rapid eyes movements (REM) and the non rapid eyes movements (NREM). Within the two phases there are four stages, of which three are NREM and the 4th is the REM itself [3].

With deprivation or decreased sleep, there are physiological changes in some systems such as cardiovascular, endocrine, respiratory and sexual. Due to these changes imbalances can occur in homeostasis [4,5], impacting physically, socially and mentally on the health of these workers [6].

It's possible to observe that the decrease or even sleep deprivation, impacts on the physical functions and also reflects on the motor part, associated with a reduction in work rhythm [7]. We can mention still the decrease in attention, concentration, increased irritability, humor changes and difficulty to establish recent memories.

The tendency of these patients to become sleepy may be the target of possible disorders such as: diabetes mellitus, hypertension, cardiovascular diseases, gastrointestinal disorders, spine problems and musculoskeletal disorders, as evidenced in this study [8].

Considering that nocturnal work activity can cause physiological, social and psychological problems, impacting directly on patient care, the evaluation of sleep patterns of nurses at nocturnal work shifts becomes necessary [9].

In this sense, the study aimed to verify and describe the consequences related to sleep disorders in nursing professionals with nocturnal activity.

\section{Method}

This is a cross-sectional, descriptive study with a quantitative approach performed at a large hospital in the city of Recife, Pernambuco. The study population was constituted by 315 nursing professionals. The sample totaled 184 participants, which 46 of them were nurses, 133 nursing technicians and 5 were excluded as losses, because they refused to fill the collection instrument.

This sample included professionals aged 18 years old and over, of both genres. All the participants should have work for more than 3 years in the current profession, in night shifts.

The evaluation instrument used was a questionnaire with 23 questions with multiple choices, which referred to: sociodemographic data (gender, age, schooling level and marital status), daily habits (routines, leisure, and morbidities presented (diseases and symptoms). 
At first, a pilot project was carried out with 30 professionals, who were excluded from the sample of 184 participants, just to evaluate possible difficulties in understanding the questions of the form and to improve the performance of the researcher responsible for the interviews.

The data collection was carried out from May to June 2015. The instrument of research was a questionnaire containing 23 questions of multiple objective choices, which questions were about socio-demographic data (gender, age, schooling level and marital status), daily habits (routines, leisure, food) and, when they appear, morbidities (diseases and symptoms).

The questionnaire was applied individually, after the explanation about the research goals. It totally lasts about 15 to 20 minutes. The researcher reads and explains the interview, solving any doubts and showing the way the responses must be given.

The data were entered in Excel spreadsheet 7.0 and later transferred to the statistical package for social sciences (SPSS) version 21 . The data were presented considering the whole group of professionals by categories, working time in night shifts, acquired diseases and associated symptoms.

The verification of the hypothesis of data normality was performed through the statistical tests of Shapiro-Wilk and the equality of variances through the Levene F-test. The results were expressed through absolute and relative frequencies in the categorical variables and of the statistical measures: average, standard deviation and variable age average.

To verify the significant difference between the professional categories according to their ages it was used the t-Student test with equal variances and, in the categorical variables, it was used the Pearson's Qui-square test or the Fisher's Exact test, when it was not possible to use the Qui-Square test. To evaluate the strength of the difference, it was obtained the odds ratio (OR) or gap ratio $(\mathrm{RC})$.

The research was approved by the Research Ethics Committee (CEP) of the Federal University of Pernambuco (UFPE) under the number CAAE: 43401315.1.00005208. All participants signed the informed consent form (TCLE), and their privacy was respected.

\section{Results}

The predominant age group was 39 to 42 years old. Most of them were female (88.3\%), unmarried $(52.5 \%)$ and had two or more children (41.9\%) (Table 1 ).

Table 1 Assessment of diseases acquired after night shifts according to the professional category.

\begin{tabular}{|c|c|c|c|c|c|c|c|c|}
\hline \multirow{3}{*}{$\begin{array}{l}\text { Variable } \\
\\
\text { Total }\end{array}$} & \multicolumn{2}{|c|}{ Total } & \multicolumn{2}{|c|}{ Nurse } & \multicolumn{2}{|c|}{ Nursing technician/Assistant } & \multirow{3}{*}{$\begin{array}{l}\text { P value } \\
\text { - }\end{array}$} & \multirow{3}{*}{$\begin{array}{l}\text { Or (IC to } 95 \%) \\
-\end{array}$} \\
\hline & & & \multirow{2}{*}{$\begin{array}{l}n \\
46\end{array}$} & \multirow{2}{*}{$\begin{array}{l}\% \\
100.0\end{array}$} & \multirow{2}{*}{$\begin{array}{l}\mathbf{n} \\
133\end{array}$} & \multirow{2}{*}{$\begin{array}{l}\% \\
100.0\end{array}$} & & \\
\hline & 179 & 100.0 & & & & & & \\
\hline \multicolumn{9}{|c|}{ Diseases acquired after night shifts? } \\
\hline Yes & 95 & 53.1 & 22 & 47.8 & 73 & 54.9 & $\mathrm{p}^{(1)}=0.408$ & $1.33(0.68$ a 2.60$)$ \\
\hline No & 84 & 46.9 & 24 & 52.2 & 60 & 45.1 & - & 1.00 \\
\hline \multicolumn{9}{|l|}{ DM } \\
\hline Yes & 8 & 4.5 & 3 & 6.5 & 5 & 3.8 & $\mathrm{p}^{(2)}=0.425$ & $1.79(0.41$ a 7.79$)$ \\
\hline No & 171 & 95.5 & 43 & 93.5 & 128 & 96.2 & - & 1.00 \\
\hline \multicolumn{9}{|c|}{ Cardiopathy } \\
\hline Yes & 3 & 1.7 & - & - & 3 & 2.3 & $\mathrm{p}^{(2)}=0.570$ & ** \\
\hline No & 176 & 98.3 & 46 & 100.0 & 130 & 97.7 & - & - \\
\hline \multicolumn{9}{|l|}{ Spine } \\
\hline Yes & 29 & 16.2 & 3 & 6.5 & 26 & 19.5 & $\mathrm{p}^{(1)}=0.039^{*}$ & 1.00 \\
\hline No & 150 & 83.8 & 43 & 93.5 & 107 & 80.5 & & $3.48(1.00$ a 12.11$)$ \\
\hline \multicolumn{9}{|c|}{ Gastrointestinal } \\
\hline Yes & 9 & 5.0 & 1 & 2.2 & 8 & 6.0 & $\mathrm{p}^{(2)}=0.451$ & ** \\
\hline No & 170 & 95.0 & 45 & 97.8 & 125 & 94.0 & - & - \\
\hline \multicolumn{9}{|c|}{ Sleep disturbance } \\
\hline Yes & 48 & 26.8 & 14 & 30.4 & 34 & 25.6 & $\mathrm{p}^{(1)}=0.520$ & 1.27 (0.61 a 2.67$)$ \\
\hline
\end{tabular}




\begin{tabular}{|c|c|c|c|c|c|c|c|c|}
\hline No & 131 & 73.2 & 32 & 69.6 & 99 & 74.4 & - & 1.00 \\
\hline \multicolumn{9}{|c|}{ Musculoskeletal } \\
\hline Yes & 17 & 9.5 & 7 & 15.2 & 10 & 7.5 & $\mathrm{p}^{(2)}=0.147$ & $2.21(0.79$ a 6.19$)$ \\
\hline No & 162 & 90.5 & 39 & 84.8 & 123 & 92.5 & - & 1.00 \\
\hline \multicolumn{9}{|c|}{ Vascular } \\
\hline Yes & 18 & 10.1 & 1 & 2.2 & 17 & 12.8 & $p^{(2)}=0.046^{*}$ & ** \\
\hline No & 161 & 89.9 & 45 & 97.8 & 116 & 87.2 & - & - \\
\hline \multicolumn{9}{|c|}{ Hypertension } \\
\hline Yes & 31 & 17.3 & 3 & 6.5 & 28 & 21.1 & $p^{(1)}=0.025^{*}$ & 1.00 \\
\hline No & 148 & 82.7 & 43 & 93.5 & 105 & 78.9 & - & $3.82(1.101$ a 3.24$)$ \\
\hline \multicolumn{9}{|c|}{ Recurrent urinary tract infection } \\
\hline Yes & 5 & 2.8 & 1 & 2.2 & 4 & 3.0 & $\mathrm{p}^{(2)}=1.000$ & ** \\
\hline No & 174 & 97.2 & 45 & 97.8 & 129 & 97.0 & - & - \\
\hline \multicolumn{9}{|c|}{ High Cholesterol } \\
\hline Yes & 11 & 6.1 & 2 & 4.3 & 9 & 6.8 & $p^{(2)}=0.731$ & $* *$ \\
\hline No & 168 & 93.9 & 44 & 95.7 & 124 & 93.2 & - & - \\
\hline \multicolumn{9}{|c|}{ Gastritis } \\
\hline Yes & 21 & 11.7 & 4 & 8.7 & 17 & 12,8 & $p^{(1)}=0.458$ & 1.00 \\
\hline No & 158 & 88.3 & 42 & 91.3 & 116 & 87.2 & - & $1.54(0.49$ a 4.84$)$ \\
\hline \multicolumn{9}{|c|}{ Depression } \\
\hline Yes & 10 & 5.6 & 1 & 2.2 & 9 & 6.8 & $\mathrm{p}^{(2)}=0.456$ & ** \\
\hline No & 169 & 94.4 & 45 & 97.8 & 124 & 93.2 & - & - \\
\hline \multicolumn{9}{|c|}{ Obesity } \\
\hline Yes & 9 & 5.0 & 2 & 4.3 & 7 & 5.3 & $p^{(2)}=1.000$ & $* *$ \\
\hline No & 170 & 95.0 & 44 & 95.7 & 126 & 94.7 & - & - \\
\hline $\begin{array}{l}\left(^{*}\right): S \\
\left({ }^{* *}\right): I \\
(1): T \\
(2): T\end{array}$ & $\begin{array}{l}\text { rence } \\
\text { sible } \\
\text { Pearso } \\
\text { r Exa }\end{array}$ & $\begin{array}{l}\text { he } 5.0^{\circ} \\
\text { termin } \\
\text { ui-squa } \\
\text { st. }\end{array}$ & Ise o & low $\mathrm{fr}$ & & & & \\
\hline
\end{tabular}

Table 2 Evaluation of sleep-related issues according to the professional category.

\begin{tabular}{|c|c|c|c|c|c|c|c|c|}
\hline \multirow[t]{3}{*}{ Variable } & \multicolumn{2}{|c|}{ Total } & \multicolumn{4}{|c|}{ Professional Category } & \multirow[t]{4}{*}{$P$ value } & \multirow[t]{4}{*}{ Odds Ratio } \\
\hline & & & \multicolumn{2}{|c|}{ Nurse } & \multicolumn{2}{|c|}{ Nursing Technician/Assistant } & & \\
\hline & & & $\mathbf{n}$ & $\%$ & $\mathbf{n}$ & $\%$ & & \\
\hline Total & 179 & 100.0 & 46 & 100.0 & 133 & 100.0 & & \\
\hline \multicolumn{9}{|c|}{ Number of cups of coffee consumed at each shift } \\
\hline None & 77 & $43 ., 0$ & 21 & 45.7 & 56 & 42.1 & $\mathrm{p}^{(1)}=0.229$ & 1.00 \\
\hline 1 to 3 & 78 & 43.6 & 16 & 34.8 & 62 & 46.6 & - & $0.69(0.33$ a 1.45$)$ \\
\hline 4 or more & 24 & 13.4 & 9 & 19.6 & 15 & 11.3 & - & $1.60(0.61$ a 4.21$)$ \\
\hline
\end{tabular}




\begin{tabular}{|c|c|c|c|c|c|c|c|c|}
\hline \multicolumn{9}{|c|}{ Number of hours the professional sleeps after night shifts } \\
\hline None & 25 & 14.0 & 8 & 17.4 & 17 & 12.8 & $\mathrm{p}^{(1)}=0.565$ & $1.25(0.36$ a 4.42$)$ \\
\hline 1 to 3 & 53 & 29.6 & 10 & 21.7 & 43 & 32.3 & - & $0.62(0.19$ a 1.99$)$ \\
\hline 4 to 6 & 79 & 44.1 & 22 & 47.8 & 57 & 42.9 & - & $1.03(0.36$ a 2.97$)$ \\
\hline 7 or more & 22 & 12.3 & 6 & 13.0 & 16 & 12.0 & - & 1.00 \\
\hline \multicolumn{9}{|c|}{ Time the professional wakes up when he's working at night } \\
\hline $\begin{array}{l}\text { Between } 4: 00 \mathrm{~h} \text { and } \\
5: 00 \mathrm{~h}\end{array}$ & 32 & 17.9 & 6 & 13.0 & 26 & 19.5 & $\mathrm{p}^{(1)}=0.454$ & 1.00 \\
\hline $\begin{array}{l}\text { Between } 5: 01 \mathrm{~h} \text { and } \\
6: 00 \mathrm{~h}\end{array}$ & 60 & 33.5 & 17 & 37.0 & 43 & 32.3 & - & $1,71(0.60$ a 4.90$)$ \\
\hline $\begin{array}{l}\text { Between } 6: 01 \mathrm{~h} \text { and } \\
8: 00 \mathrm{~h}\end{array}$ & 55 & 30.7 & 17 & 37.0 & 38 & 28.6 & - & $1.94(0.67$ a 5.57$)$ \\
\hline More than $8: 00 \mathrm{~h}$ & 32 & 17.9 & 6 & 13.0 & 26 & 19.5 & - & $1.00(0.28$ a 3.51$)$ \\
\hline \multicolumn{9}{|c|}{ During the past month, how would you rate the quality of your sleep? } \\
\hline Very bad & 14 & 7.8 & 3 & 6.5 & 11 & 8.3 & $\mathrm{p}^{(1)}=0.924$ & 1.00 \\
\hline Bad & 78 & 43.6 & 20 & 43.5 & 58 & 43.6 & - & $1.26(0.32$ a 5.00$)$ \\
\hline Good/Very good & 87 & 48.6 & 23 & 50.0 & 64 & 48.1 & - & $1.32(0.34$ a 5.15$)$ \\
\hline \multicolumn{9}{|c|}{ Do you take any sleeping pills prescribed by your doctor, indicated by someone else or even on your own? } \\
\hline Yes & 14 & 7.8 & 1 & 2.2 & 13 & 9.8 & $p^{(2)}=0.120$ & $* *$ \\
\hline No & 165 & 92.2 & 45 & 97.8 & 120 & 90.2 & - & \\
\hline \multicolumn{9}{|c|}{ Are the staff bedrooms conditions satisfactory? Are they enough for your needs? } \\
\hline Yes & 45 & 25.1 & 14 & 30.4 & 31 & 23.3 & $\mathrm{p}^{(1)}=0.337$ & $1.44(0,68$ a 3.03$)$ \\
\hline No & 134 & 74.9 & 32 & 69.6 & 102 & 76.7 & - & 1.00 \\
\hline \multicolumn{9}{|c|}{ Do the night shifts harm your humor? } \\
\hline Yes & 98 & 54.7 & 28 & 60.9 & 70 & 52.6 & $p(1)=0.333$ & $1.40(0.71$ a 2.77$)$ \\
\hline No & 81 & 45.3 & 18 & 39.1 & 63 & 47.4 & - & 1.00 \\
\hline
\end{tabular}

When asked if they attended an educational institution, 72.1\% said no. The majority of people interviewed (40\%) finished their courses more than 20 years ago (Table 2). (49.2\%) had two jobs; $(36.9 \%)$ of the people interviewed had less than five years of night shift work?

\section{Discussion}

The people researched was between 39 and 42 years old; $88.3 \%$ of them were women, $52.5 \%$ single and the remaining $47.5 \%$ were married or in a stable union, in agreement to the study published in 2010 by the COFEN (Federal Nursing Council), that presented $42.29 \%$ of single people. Most of them had two jobs and were technical level workers.

Part of them consumes 1 to 3 cups of coffee during a night work. Corroborating Martino's study, in which $60 \%$ of the workers did the same to decrease sleep and accumulated fatigue because of a tiring activity, stimulating the brain to keep awake.

Half of respondents rated sleep quality as poor/very poor, in agreement with Martino, who affirmed that $60 \%$ to $70 \%$ of respondents complain of behavioral changes, insomnia or somnolence, which impacts on their quality of sleep [6]. This deprivation affects mood and quality of life, with a decrease in reactions, increasing fatigue, making the nursing professional more susceptible to accidents [7].

An important factor associated with sleep quality is the room conditions for nursing rest that are unsatisfactory for most respondents $(74.9 \%)$. They reported that the space is small for the group, the amount of beds inadequate, inappropriate ventilation, presence of insects and lack of bed linen.

With deprivation or decreased sleep, changes may occur in the body, which, at the beginning, may present, in a short term, manifestations such as drowsiness and tiredness during the day, 
episodes of irritability, mood changes, loss of recent memory, slow thinking, lack of attention and difficulty concentrating, thus harming creativity, planning and ability to execute tasks [10].

Over the years, chronicity of these changes may occur, increasing the occurrence of changes in physical vigor, decreased muscle tone, premature aging, impaired immune system, obesity development, musculoskeletal disorders, diabetes mellitus, cardiovascular disorders (the most common is hypertension) and gastrointestinal disorders (diarrhea, intestinal constipation) [11].

During sleep cycles, physiological systems and functions change (REIMAO). At each stage of sleep (REM and NREM) different responses occur in the body, which will be mentioned:

Memory: In REM sleep phase as NREM the memories of what happened during the day are sedimented. When you do not sleep well you may forget some facts, for example, where you put the objects or even the names of some people. The person becomes more disconnected, because sleep interferes in the brain, especially in the thermal regulation, a fundamental function for the performance of memory mechanisms [12].

Cardiovascular functions: There may be some problems related to circulation. We can mention hypertension as a harmful factor to the health of night shift workers, because the reduction or deprivation of sleep, cortisol and adrenaline are released into the bloodstream, and they decrease the release of melatonin, which is an important sleep inducer. These substances have a vasoconstricting characteristic in the blood vessels increasing the chances of the worker to develope hypertension [12].

Respiratory functions: During REM sleep, apnea and hypoventilation disorders can occur, resulting in a faster and more irregular breathing [12].

Gastrointestinal functions: Leptin is a hormone responsible for reducing food intake at night, decreasing energy, glucose and lipid metabolism and organizing neuroendocrine function. 12 With night shifts, occurs the deprivation of sleep, which inhibits the production of leptin and increases renin, which is the hormone responsible for increased appetite, leading to increased intake of carbohydrates, lipids and sugars that can cause obesity in this class of professionals.

Endocrine functions: During the sleep-wake cycle, important hormones are secreted, such as: growth hormone $(\mathrm{GH})$, renin, prolactin and TSH. We can also mention cortisol, which is a hormone released by the adrenals; responsible for the metabolism of proteins, carbohydrates and lipids and has antiinflammatory function. However, when it is secreted in a different quantity and time than usual, it has opposite effects, generating in the body effects similar to stress, which can cause the loss of physical performance and decreased perception [12].
Musculoskeletal system: Nursing professionals do their activities in hospitals and those activities enhance the use of the skeletal muscle system. The repetitive movements, using of physical resources, inadequate positions make these workers developing work-related illnesses [8], with this they present symptoms as: back pain, joint pain, predisposition for herniated disc, tendinitis and very muscular fatigue [13].

It was observed in this study that $53.1 \%$ of the workers watched the appearance of morbidities such as: sleep disturbances (26.8\%), hypertension (17.3\%), and spinal problems \%) and gastrointestinal (15.7\%) and vascular (11.8\%) conditions. The nursing technicians' category was the most affected with $54.9 \%$, due to their assignments requiring more waking time, for their assistance to the patients, sedimenting what was expected with this study.

\section{References}

1. Rechtschaffen A, Bergmann BM (2002) Sleep deprivation in the rat: an update of the 1989 paper. Sleep 25: 18-24.

2. Chokroverty S (2010) Overview of sleep \& sleep disorders. Indian J Med Res 131: 126-140.

3. Mignot E, Taheri S, Nishino S (2002) Sleeping with the hypothalamus: Emerging therapeutic targes for sleep disorders. Nat Neurosci 5: 1071-1075.

4. Pace-Schott EF, Hobson JA (2002) The neurobiology of sleep: Genetics, cellular physiology and subcortical networks. Nature Neuroscience 3: 591-605.

5. Saper C, Chou TC, Scammell TE (2001) The sleep switch: Hypothalamic control of sleep and wakefulness. Trends Neurosci 24: 726-731.

6. Araujo AJ (2007) Shift and night shift work and chronobiology.

7. Silva CAR, De Martino MMF (2009) Aspects of the wake-sleep cycle and emotional states in nurses of different work shifts.

8. Manhaes VMS (2009) Chronotype and sleep deprivation in night hospital nursing service workers.

9. De Martino MMF (2002) Comparative Study of Sleep Patterns in Nursing Workers in Day and Night Shifts. Rev Panam Salud Publica 12: 95-99.

10. Parada OE, Alexandre NMC, Benatti MCC (2002) Occupational injuries affecting the spine in nursing service workers.

11. Regis GIF (1998) Maladaptation maladaptation syndrome: An ergonomic approach.

12. Reimao RJ, La Rocca PF, Silveira AM, Bonilla IML, Gine NA (2003) Factors related to nursing absenteeism in nursing professionals. Rev Saude Publica 37: 616-623.

13. Campos MLP, Martino MMF (2004) Chronobiological aspects of wake cycle and anxiety levels of nurses in different work shifts. Rev Esc Enferm USP 38: 415-421. 